\title{
Simultaneous Determination of $S$-Methylmethionine, Vitamin U and Free Amino Acids in Extracts of Green Tea with an HPLC-Amino Acid Analyzer
}

\author{
Kozo Ohtsuki, Makoto Kawabata, Hiroshi Kokura* \\ and Kuniko TAGUCHI \\ Department of Food Science, Faculty of Living Science, Kyoto Prefectural University, \\ Shimogamo, Kyoto 606, Japan \\ *Kyoto Prefectural Tea Research Institute, Shirakawa, \\ Uji, Kyoto 611, Japan \\ Received April 7, 1987
}

\begin{abstract}
Free amino acids and $S$-methylmethionine (MMS, an anti-ulcer factor, Vitamin U) in green tea extracts were simultaneously determined with an HPLC-amino acid analyzer using lithium citrate buffers.

Rapid analysis of MMS and free amino acids was achieved with a high resolution column, MCI Gel CK-10U $0.46 \phi \times 15 \mathrm{~cm}$, within $180 \mathrm{~min}$. MMS in the column eluates was identified as dimethyl sulfide by a gas-chromatographic method with a flame photometric detector. The contents of MMS and free amino acids in various green teas were determined and compared with respect to the quality of commercial teas, blended teas and non-blended teas, and the place of cultivation of the tea. The described method is rapid and useful for checking the quality of green tea.
\end{abstract}

Various vegetables ${ }^{1 \sim 5)}$ and green tea ${ }^{4,6,7)}$ contain as much S-methylmethionine (MMS, an anti-ulcer factor, vitamin $\mathrm{U}$ ) as free amino acids. MMS was also reported to have been detected in a soybean-meal hydrolyzate after neutralization. ${ }^{8,9)}$ In this case, MMS was thought to be an undesirable by-product and to be formed from methionine and pectin methyl ester during the acid-hydrolysis of the soybean meal.

In the previous paper, ${ }^{7)}$ a rapid analytical method for MMS in extracts of various green teas, oolong teas and black tea was reported, involving cation-exchange chromatography, and the conditions for extraction of MMS from green tea and the heat-stability of MMS in the green-tea extracts were also described.

We have also determined the quantity of dimethylsulfide (DMS), which is formed from MMS in shaded green teas (Ooi-cha), such as Gyokuro and high-grade Sen-cha, ${ }^{10)}$ by flame photometric detection (FPD) with a gaschromatograph. ${ }^{11)}$
This paper describes analyses of MMS as well as free amino acids in extracts of green teas on the same chromatogram or by the more rapid analytical method for MMS, using an HPLC-amino acid analyzer. Some analytical data for green teas of commercial sources and some kinds of non-blended green teas cultivated and processed in Kyoto Pref. Tea Res. Inst. or in other places are also presented.

\section{MATERIALS AND METHODS}

Materials. Green teas (various Sen-cha, \#1 \#5, at prices of $¥ 1,500 \sim ¥ 250$ per $100 \mathrm{~g}$ ) were purchased from a shop in Kyoto Pref. The other Sen-chas, \#6 and \#7, were purchased at prices of $¥ 600$ and $¥ 1,000$ from Gifu Pref. and Shimane Pref., respectively. These commercial teas are thought to be blended ones. Non-blended teas, Gyokuro and Sen-cha, \#8 \#11, were cultivated and processed at Kyoto Pref. Tea Res. Inst. The other non-blended teas, $\# 12 \sim \# 14$, were cultivated and processed at farms in Kyoto Pref., Nara Pref. and Shizuoka Pref.

Authentic amino acids were obtained from Sigma (USA). MMS and the other chemicals were purchased from Nakarai Chem. Co. (Kyoto). 
Extraction of MMS and free amino acids. Five hundred $\mathrm{mg}$ of green tea, powdered and filtered through a $0.5 \mathrm{~mm}$ mesh sieve, was suspended in $10 \mathrm{ml}$ of distilled water at $60^{\circ} \mathrm{C}$ for $30 \mathrm{~min}$ with agitation. The suspension was then centrifuged at $3000 \mathrm{rpm}$ for $10 \mathrm{~min}$. The precipitate was reextracted and then centrifuged again as above. Afrer the centrifugation, the precipitate was washed with water at $80^{\circ} \mathrm{C}$. The supernatants and washings were combined and then filtered through a Toyo membrane filter (Toyoroshi Co. TM-2P, $0.45 \mu \mathrm{m}$ pore size) before injection into the amino acid analyzer.

Determination of MMS and free amino acids. Amino acid analyses of the extracts were carried out with a Shimadzu HPLC, LC-6A, modified for amino acid analysis of physiological-fluids, see Fig. 1, in our laboratory under the following conditions; a stainless steel column $(0.46 \phi \times 15 \mathrm{~cm})$ of Mitsubishi MCI Gel CK-10U $(5 \mu \mathrm{m}$ particle size) at $40^{\circ} \mathrm{C}$, and elution buffers of $0.15 \mathrm{~N} \mathrm{Li}-$ citrate, $\mathrm{pH} 2.75,0.25 \mathrm{~N} \mathrm{Li}$-citrate, $\mathrm{pH} 3.9,0.8 \mathrm{~N}$ Li-citrate, pH 3.4, $1.0 \mathrm{~N} \mathrm{Li}$-citrate, $\mathrm{pH} 4.05$, and $0.2 \mathrm{~N} \mathrm{LiOH}$ at a flow rate of $0.5 \mathrm{ml} / \mathrm{min}$, and the conventional ninhydrin solution $^{12)}$ at a flow rate of $0.25 \mathrm{ml} / \mathrm{min}$. Calculation of the peak areas on the chromatograms was carried out with a Chromatopac C-R3A (Shimadzu). When MMS was to be determined by the other method or needed to be analyzed rapidly, another analytical method was used, see Fig. 3; a stainless steel column of MCI Gel CK-10S $(0.46 \phi \times 10 \mathrm{~cm})$ at $50^{\circ} \mathrm{C}$ with $0.35 \mathrm{~N} \mathrm{Na}$ citrate, $\mathrm{pH} 6.5$, and the ninhydrin solution at flow rates of $0.5 \mathrm{ml} / \mathrm{min}$ and $0.25 \mathrm{ml} / \mathrm{min}$, respectively.

Identification of MMS. with the HPLC-amino acid ana- lyzer eluates. The detection and identification of MMS in the eluates was carried out in the same manner with a gaschromatographic apparatus as in the previous study. ${ }^{7)}$ DMS, which is one of the decomposition products of MMS on heat treatment in alkaline medium, was separated on a column of Shimalite TPA $(60 \sim 70$ mesh $)$ coated with $10 \% 1,2,3$-TCEP, $3 \mathrm{~mm} \phi \times 3 \mathrm{~m}$, and then detected by FPD at $394 \mathrm{~nm}$, which is a wavelength specific and sensitive for sulfur compounds: ${ }^{11)}$

\section{RESULTS AND DISCUSSION}

A flow diagram of the HPLC-amino acid analyzer used for the analysis of MMS and free amino acids is shown in Fig. 1. The specified inner volume of the Teflon tube in the reaction bath was the maximum, in order to maintain the high resolution ability of the column, though the increased volume improved the color-yield of the ninhydrin reaction.

Since a green-tea extract contains free, ordinary amino acids and specific amino acids such as theanine ${ }^{13)}$ and $\gamma$-aminobutyric acid, which cannot be separated from other amino acids with the conventional column and $\mathrm{Na}-$ citrate buffer system, it is indispensable to use a Li-citrate buffer system. ${ }^{14 \sim 19)}$

In our previous study, MMS was easily

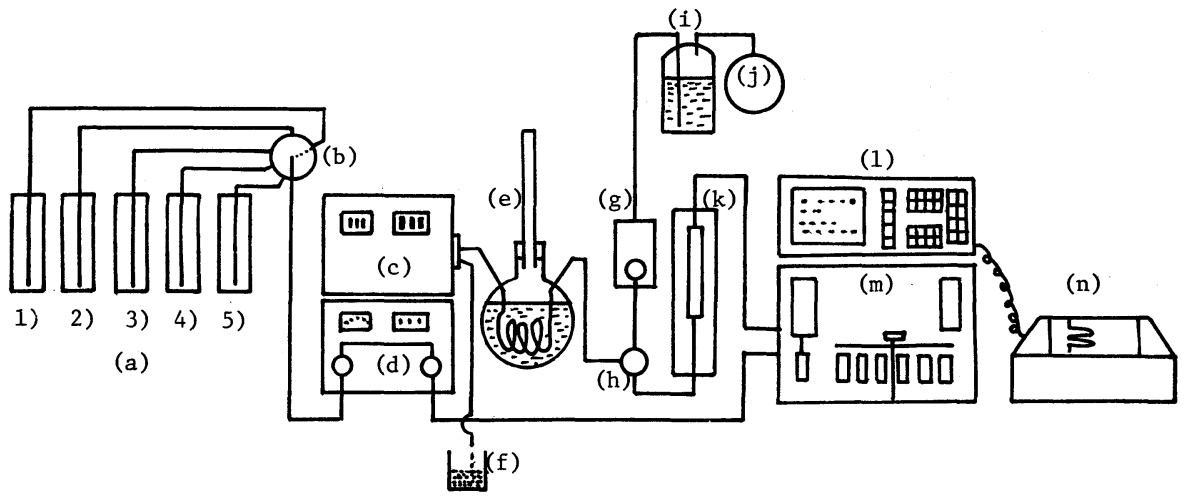

FIG. 1. Flow Diagram of the HPLC for the Analysis of Free Amino Acids and MMS.

(a) Buffer reservoirs: 1) 4) elution buffers; 5) $0.2 \mathrm{~N} \mathrm{LiOH.} \mathrm{(b)} \mathrm{Buffer} \mathrm{selector,} \mathrm{changed} \mathrm{with} \mathrm{a} \mathrm{system}$ controller, SCL-6A. (c) UV-VIS spectrophotometric detector, Shimadzu SPD-6AV. (d) Eluent pump, Shimadzu LC-6A. (e) Reaction bath, $0.5 \mathrm{~mm} \phi \times 5 \mathrm{~m}$ Teflon tube in boiling water. (f) Waste. (g) Ninhydrin pump, Kyowa Seimitsu KHD-16. (h) T-Shaped mixer. (i) Ninhydrin solution. (j) Nitrogen gas. (k) Separation column, Mitsubishi MCI Gel CK-10U, $0.46 \phi \times 15 \mathrm{~cm}$, with a constant-temperature bath at $40^{\circ} \mathrm{C}$. (1) System controller, Shimadzu SCL-6A. (m) Auto injector, Shimadzu Sil-6A. (n) Recording integrator, Shimadzu Chromatopac C-R3A. 


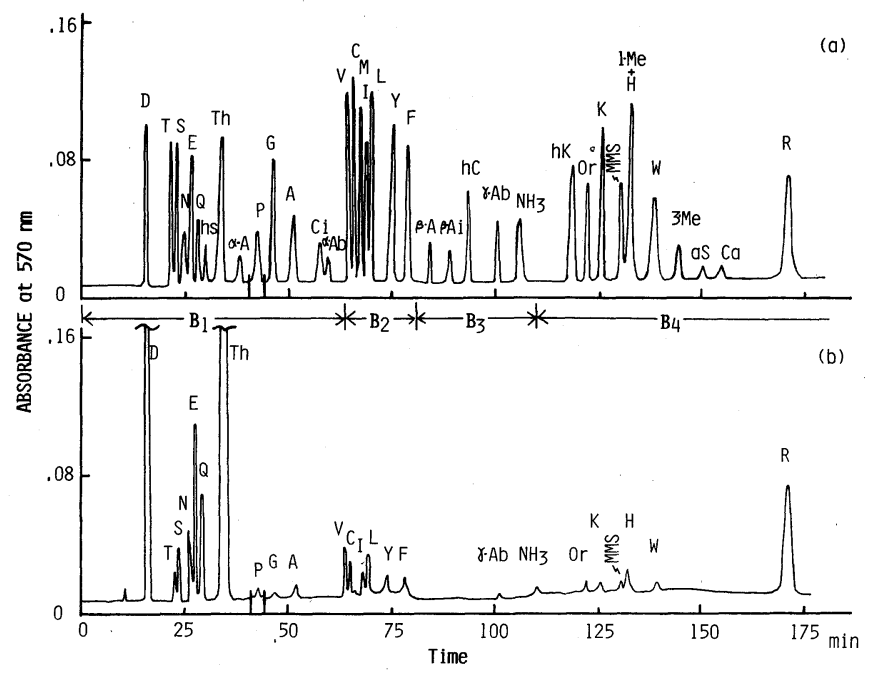

FIG. 2. Chromatograms of Standard Amino Acids and Tea Extracts.

$\mathrm{B}_{1}, 0.15 \mathrm{~N}$ Li-citrate, $\mathrm{pH} 2.75 ; \mathrm{B}_{2}, 0.25 \mathrm{~N} \mathrm{Li-citrate,} \mathrm{pH} 3.9 ; \mathrm{B}_{3}, 0.8 \mathrm{~N} \mathrm{Li}$-citrate, $\mathrm{pH} 3.4 ; \mathrm{B}_{4}, 1.0 \mathrm{~N}$ Li-citrate, $\mathrm{pH}$ 4.1. Abbreviations. hS, homoserine; Th, theanine; $\alpha$-A, $\mathrm{L}-\alpha$-amino adipic acid; Ci, L-citrulline; $\alpha$-Ab, $\mathrm{L}-\alpha$ amino butyric acid; $\beta$-A, $\beta$-alanine; $\beta$-Ai, DL- $\beta$-amino-iso-butyric acid; hC, L-homocystine; $\gamma$-Ab, $\gamma$-amino- $n$ butyric acid; hK, $\delta$-hydroxy-lysine; Or, L-ornithine; 1-Me, 1-methyl-L-histidine; 3-Me, 3-methyl-L-histidine; aS, L-anserine; Ca, L-carnosine; Ordinary amino acids, abbreviated as one letter. (a) Standard amino acids and MMS. (b) Green-tea extract (Sen-cha).

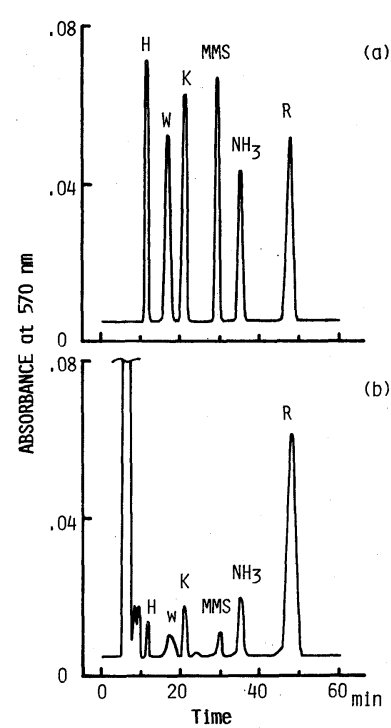

FIG. 3. Chromatograms of Standard Amino Acids and a Tea Extract with a Rapid Analytical Method.

Column, Mitsubishi MCI Gel CK10S, $0.46 \phi \times 10 \mathrm{~cm}$, at $50^{\circ} \mathrm{C}$; buffer, $0.35 \mathrm{~N} \mathrm{Na-citrate,} \mathrm{pH}$ 6.5. (a) Standard amino acids. (b) Green-tea extract (Sen-cha).

analyzed by lowering the temperature of the column, but it is time-consuming, taking about $4 \mathrm{hr}$ per one sample, and it is a mono-purpose

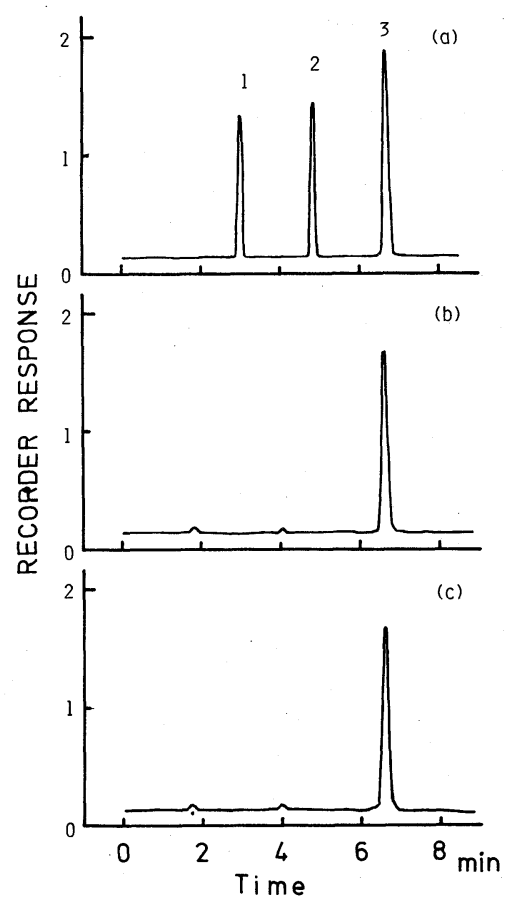

FIG. 4. Gas-chromatograms of Headspace Vapor of the Column Eluates.

(a) Standard sulfur compounds: 1, hydrogen sulfide; 2, methylmercaptan; 3, dimethyl sulfide. Headspace vapor of the alkaline- and heat-treated column eluate fractions of MMS in Fig. 2a or Fig. 3a (b); and in Fig. 2b or Fig. 3b (c). 
Table 1. Amino Acid and MMS Contents of Commercial Green Teas

\begin{tabular}{|c|c|c|c|c|c|c|c|c|}
\hline & \multicolumn{8}{|c|}{ Sen-cha } \\
\hline & $\# 1$ & $\# 2$ & $\# 3$ & $\# 4$ & $\# 5$ & $\# 6$ & $\# 7^{a}$ & \\
\hline$A s p^{b}$ & 478 & 383 & 264 & 329 & 151 & 429 & 193 & $\left(\mathrm{mg}^{\mathrm{o}} \mathrm{o}\right)$ \\
\hline Thr & 49 & 52 & 13 & 54 & 11 & 16 & 14 & \\
\hline Ser & 113 & 114 & 80 & 90 & 50 & 62 & 50 & \\
\hline Asn & 80 & 128 & 46 & 93 & 33 & 47 & 4 & \\
\hline Glu & 440 & 341 & 404 & 448 & 184 & 370 & 209 & \\
\hline Gln & 337 & 575 & 164 & 118 & 40 & 198 & 104 & \\
\hline Thea & 2725 & 2357 & 1258 & 982 & 437 & 1153 & 830 & \\
\hline Pro & 25 & 19 & 18 & 18 & 11 & 8 & 7 & \\
\hline Gly & 6 & 11 & 2 & 4 & 6 & 4 & 4 & \\
\hline Ala & 49 & 43 & 44 & 65 & 34 & 39 & 21 & \\
\hline Val & 37 & 84 & 38 & 42 & 48 & 46 & 15 & \\
\hline Cys & 30 & 25 & 20 & 18 & 15 & 7 & 1 & \\
\hline Met & 9 & 2 & 1 & $\operatorname{tr}$ & $\operatorname{tr}$ & 2 & $\operatorname{tr}$ & \\
\hline Ile & 24 & 22 & 10 & 23 & 9 & 34 & 11 & \\
\hline Leu & 31 & 27 & 11 & 21 & 8 & 40 & 14 & \\
\hline Tyr & 46 & 47 & 13 & 28 & 24 & 44 & 19 & \\
\hline Phe & 43 & 53 & 81 & 24 & 27 & 49 & 21 & \\
\hline GABA & 19 & 17 & 15 & 14 & 6 & 15 & 9 & \\
\hline $\mathrm{NH}_{3}$ & 32 & 37 & 58 & 72 & 3 & 14 & 20 & \\
\hline Orn & 7 & 9 & 8 & 5 & 2 & 6 & 4 & \\
\hline Lys & 37 & 44 & 16 & 22 & 13 & 37 & 14 & \\
\hline MMS & 9 & 6 & 3 & 5 & 3 & 6 & 4 & \\
\hline $\mathrm{His}$ & 24 & 72 & 34 & 12 & 8 & 21 & 11 & \\
\hline Trp & 31 & 36 & 23 & 38 & 24 & 27 & 9 & \\
\hline Arg & 464 & 336 & 194 & 149 & 30 & 334 & 155 & \\
\hline Total & 5145 & 4840 & 2818 & 2674 & 1177 & 3008 & 1743 & \\
\hline Grade $^{c}$ & A & A & B & B & $\mathrm{C}$ & A & B & \\
\hline
\end{tabular}

a $\quad$ Teas \#1 \#5 were manufactured and sold at a shop in Kyoto Pref. Teas \#6 and \#7 were sold in Gifu Pref. and Shimane Pref., respectively.

${ }^{b}$ Abbreviations: Thea, theanine; GABA, $\gamma$-aminobutyric acid; Orn, ornithine; tr, trace.

c A, high quality; B, medium quality; C, ordinary quality. Judged by organoleptic testing at the time when the teas were bought.

method, that is, other amino acids cannot be determined at the same time. ${ }^{7)}$

To improve these points, in this study, rapid analysis of MMS as well as other specific amino acid derivatives was attained by using an HPLC-column packed with the cationexchange resin of smaller particle size, $5 \mu \mathrm{m}$, and an HPLC apparatus, Shimadzu LC-6A.

A chromatogram of standard MMS and the amino acids which are found in physiological fluids is presented in Fig. 2(a).

A proline peak was detected at $440 \mathrm{~nm}$ with an automatic wavelength changeable photometer, Shimadzu SPD-6AV. In Fig. 2(a), homoserine, which is one of the decomposition products of MMS, was also separated from glutamine. However, even when an excess amount of a green-tea extract, Sen-cha, was applied, as shown in Fig. 2(b), almost no homoserine was detected, that is, MMS was 
Table II. Amino Acid and MMS Contents of Non-blended Green Teas

\begin{tabular}{|c|c|c|c|c|c|c|c|c|}
\hline & \multicolumn{2}{|c|}{ Gyokuro } & \multicolumn{6}{|c|}{ Sen-cha } \\
\hline & $\# 8$ & $\# 9$ & $\# 10$ & $\# 11$ & $\# 12$ & $\# 13$ & $\# 14^{a}$ & \\
\hline $\mathrm{Asp}^{b}$ & 546 & 283 & 185 & 145 & 449 & 180 & 355 & $\left(\mathrm{mg}^{\circ} \%\right)$ \\
\hline Thr & 46 & 33 & 27 & 20 & 58 & 9 & 24 & \\
\hline Ser & 117 & 88 & 51 & 54 & 92 & 51 & 64 & \\
\hline Asn & 590 & 344 & 49 & 28 & 193 & 23 & 53 & \\
\hline Glu & 511 & 275 & 293 & 203 & 564 & 193 & 330 & \\
\hline Gln & 418 & 258 & 358 & 134 & 323 & 78 & 92 & \\
\hline Thea & 2245 & 1926 & 1317 & 902 & 2327 & 905 & 994 & \\
\hline Pro & 8 & 29 & 10 & 18 & 12 & 21 & 8 & \\
\hline Gly & 7 & 3 & 2 & 4 & 4 & 2 & 3 & \\
\hline Ala & 78 & 46 & 34 & 19 & 50 & 17 & 48 & \\
\hline Val & 62 & 25 & 31 & 17 & 26 & 13 & 39 & \\
\hline Cys & 29 & 16 & 20 & 11 & 2 & 18 & 8 & \\
\hline Met & $\operatorname{tr}$ & $\operatorname{tr}$ & 2 & 1 & 1 & 2 & 2 & \\
\hline Ile & 50 & 14 & 16 & 8 & 36 & 8 & 30 & \\
\hline Leu & 43 & 15 & 8 & 9 & 21 & 9 & 28 & \\
\hline Tyr & 48 & 15 & 18 & 9 & 16 & 15 & 30 & \\
\hline Phe & 45 & 17 & 14 & 10 & 14 & 16 & 26 & \\
\hline GABA & 10 & 12 & 13 & 16 & 11 & 12 & 23 & \\
\hline $\mathrm{NH}_{3}$ & 6 & 4 & 8 & 5 & 37 & 8 & 11 & \\
\hline Orn & 15 & 6 & 5 & 3 & 5 & 4 & 3 & \\
\hline Lys & 57 & 23 & 12 & 11 & 20 & 13 & 29 & \\
\hline MMS & 9 & 4 & 4 & 12 & 6 & 8 & 11 & \\
\hline His & 36 & 10 & 15 & 37 & 40 & 10 & 16 & \\
\hline $\operatorname{Trp}$ & 55 & 24 & 14 & 4 & 30 & 7 & 19 & \\
\hline Arg & 781 & 288 & 292 & 80 & 632 & 132 & 151 & \\
\hline Total & 5812 & 3758 & 2798 & 1760 & 4969 & 1754 & 2397 & \\
\hline Grade $^{c}$ & A & B & A & B & A & $\mathrm{C}$ & B & \\
\hline
\end{tabular}

a Teas \#8 \#11 were cultivated and processed at Kyoto Pref. Tea Inst. \#12, \#13 and \#14 were manufactured in Kyoto Pref., Nara Pref. and Shizuoka Pref., respectively.

$b, c$ Abbreviations the same as in Table I.

scarcely decomposed in the green-tea extract.

Theanine was the most abundant amino acid in all the green-tea extracts, as shown in Fig. 2(b), and Tables I and II.

Aspartic acid, serine, asparagine, glutamic acid, glutamine and arginine were abundant in the extracts, amounting to about one-tenth of their total amino acid quantity, respectively, as shown in Tables I and II.

Other minor component amino acids were also detected, as can be seen in Fig. 2(b).

The results with another rapid MMS de- termination method, with an analysis time of 30 min, are shown in Fig. 3. This is a modification of the former method, with a $0.6 \phi \times 8.5 \mathrm{~cm}$ column and $\mathrm{Na}$-citrate buffer. ${ }^{7)}$

The pooled MMS fractions in Fig. 2(a) or Fig. 3(a) were heated at $100^{\circ} \mathrm{C}$ for $10 \mathrm{~min}$ in the alkaline medium ${ }^{7}$ and then the headspace vapor was analyzed by gas-chromatography, as shown in Fig. 4(b). In the same manner, the pooled MMS fractions in Fig. 2(b) or Fig. 3(b) were treated and analyzed, as shown in Fig. 4(c). The results confirmed the presence of 
MMS.

The amino acid contents of the commercial green teas are shown in Table I. The theanine contents of \#1, \#2, \#3 and \#7 comprised as much as about $50 \%$ of the total amino acids, respectively. The arginine contents varied with the sample; in high quality green teas \#1, \#2, $\# 6$, \#8, \#10 and \#12, it amounted to about $10 \%$ of the total amino acids, respectively.

Commercial green teas are usually produced by blending of green teas from several sources, to improve the quality of the tea. To compare blended green teas with non-blended ones, the analytical data for the latter are summarized in Table II. Non-blended green teas also contained as much theanine, arginine, glutamic acid, glutamine and aspartic acid as the commercial ones, that is, the same tendency was observed. The theanine and arginine contents were reported to be influenced by ammonium fertilizer used during the cultivation of the green tea plants. ${ }^{18)}$ The data for the nonblended green teas, Table II, showed that the quality, such as the taste, reflected the amino acid content, which was determined by the cultivation conditions. Takeo ${ }^{18)}$ also reported that the spring shoots of tea plucked in India did not contain arginine, and he assumed that the reason was the lack of ammonium fertilizer. Tables I and II show that every green tea cultivated in Japan contained arginine to various extents, and this reflected the ammonium fertilizer application during cultivation.

Sen-chas \#1, \#11 and \#14, and Gyokuro \#8 contained more MMS than the others, and this amino acid was abundant in fresh, high-grade green tea, as reported previously. ${ }^{7)}$
Acknowledgments. We wish to thank Misses $\mathrm{K}$. Matsumoto, Y. Doi and E. Nakajima for their help in performing part of the study.

\section{REFERENCES}

1) F. Challenger and B. Hayward, Chem. Ind. (London), 25, 729 (1954).

2) R. McRorie, C. L. Sutherland, M. S. Lewis, A. D. Barton, M. R. Glazener and W. Shive, J. Am. Chem. Soc., 76, 115 (1954).

3) E. Hiraoka and T. Kishi, Vitamins, 28, 387 (1963).

4) F. I. Skodak, F. F. Wong and L. M. White, Anal. Biochem., 13, 568 (1965).

5) E. G. Kovatcheva, Analyst, 104, 79 (1979).

6) T. Kiribuchi and T. Yamanishi, Agric. Biol. Chem., 27, 56 (1963).

7) K. Ohtsuki, M, Kawabata, K. Taguchi, H. Kokura and S. Kawamura, Agric. Biol. Chem., 48, 2471 (1984).

8) Y. Obata and J. Mizutani, Agric. Biol. Chem., 25, 36 (1961).

9) T. Hino, A. Kimizuka, K. Ito and T. Ogasawara, $J$. Agric. Chem. Soc. Jpn., 36, 413 (1962).

10) M. Kawabata, K. Ohtsuki, H. Kokura and Y. Wakahara, Agric. Biol. Chem., 41, 2285 (1977).

11) S. S. Brody and J. E. Chaney, J. Gas Chromatogr., 4, 42 (1966).

12). S. Moore, D. H. Spackman and W. H. Stein, Anal. Chem., 30, 1185 (1958).

13) Y. Sakato, J. Agric. Chem. Soc. Jpn., 23, 262 (1949).

14) S. Kato and T. Suzuki, J. Jap. Soc. Food Sci. Technol., 18, 30 (1971).

15) M. Nakagawa and N. Ishida, J. Jap. Soc. Food Sci. Technol., 20, 119 (1973).

16) E. Kubota and M. Nakagawa, Chagyo Gijutsu Kenkyu, 45, 51 (1973).

17) S. Hirose and S. Tamada, Chagyo Kenkyu Hokoku, 49, 61 (1979).

18) T. Takeo, Chagyo Gijutsu Kenkyu, 56, 70 (1979).

19) T. Nagata and S. Sakai, Japan J. Breed, 34, 459 (1984). 